\title{
Intensification Variability of Tropical Cyclones in Directional Shear Flows: Vortex Tilt-Convection Coupling
}

\author{
JIAN-FENG GU \\ Key Laboratory of Mesoscale Severe Weather, Ministry of Education, and School of \\ Atmospheric Sciences, Nanjing University, Nanjing, China, and Department of Meteorology, \\ University of Reading, Reading, United Kingdom \\ ZHE-Min TAN AND XIN QIU \\ Key Laboratory of Mesoscale Severe Weather, Ministry of Education, and School of \\ Atmospheric Sciences, Nanjing University, Nanjing, China
}

(Manuscript received 16 September 2018, in final form 3 May 2019)

\begin{abstract}
The coupling of vortex tilt and convection, and their effects on the intensification variability of tropical cyclones (TCs) in directional shear flows, is investigated in this study. The height-dependent vortex tilt controls TC structural differences in clockwise (CW) and counterclockwise (CC) hodographs during their initial stage of development. Moist convection may enhance the coupling between displaced vortices at different levels and thus reduce the vortex tilt amplitude and enhance precession of the overall vortex tilt during the early stage of development. However, differences in the overall vortex tilt between $\mathrm{CW}$ and $\mathrm{CC}$ hodographs are further amplified by a feedback from convective heating and therefore result in much higher intensification rates for TCs in CW hodographs than those in CC hodographs. In CW hodographs, convection organization in the left-of-shear region is favored because the low-level vortex tilt is ahead of the overall vortex tilt and the TC moves to the left side of the deep-layer shear. This results in a more humid midtroposphere and stronger surface heat flux on the left side (azimuthally downwind) of the overall vortex tilt, thus providing a positive feedback and supporting continuous precession of the vortex tilt into the upshearleft region. In CC hodographs, convection tends to organize on the right side (azimuthally upwind) of the overall vortex tilt because the low-level vortex tilt is behind the overall vortex tilt and the TC moves to the right side of the deep-layer shear. In addition, convection organizes radially outward near the downshearright region, which weakens convection within the inner region. These configurations lead to a drier midtroposphere and weaker surface heat flux in the downwind region of the overall vortex tilt and also a broader potential vorticity skirt. As a result, a negative feedback is established that prevents continuous precession of the overall vortex tilt.
\end{abstract}

\section{Introduction}

Environmental directional shear flows that change wind direction with height can result in significant variability of the intensification rate of tropical cyclones (TCs). Tropical cyclones intensify more rapidly in clockwise $(\mathrm{CW})$ hodographs than in counterclockwise (CC) hodographs, even if the deep-layer shear between 200 and $850 \mathrm{hPa}$ is identical (Nolan 2011, hereafter N11). It is important to understand the physics that underlies the uncertainties of TC intensification in directional shear flows, as environmental flows in the real atmosphere are more

Corresponding author: Zhe-Min Tan, zmtan@nju.edu.cn complicated than idealized unidirectional shear flows (e.g., Wang et al. 2015).

Distinct TC structural features (e.g., local helicity, the position of convection, surface heat flux relative to the deep-layer shear) have been identified to be responsible for variations in convective heating and the precession of convection, thus leading to variability in TC intensification in directional shear flows (Onderlinde and Nolan 2014, 2016; hereafter ON14, ON16). Recently, Gu et al. (2018, hereafter GTQ18) showed that TC structural differences in $\mathrm{CW}$ and $\mathrm{CC}$ hodographs are rooted in dry dynamics; that is, they arise from a balanced response to distinct configurations of heightdependent vortex tilt in directional shear flows, particularly 
low-level vortex tilt relative to the overall vortex tilt. However, the extent to which vortex tilt-dominated dynamics can explain structural features in moist simulations remains unclear. For example, it is not obvious how dry dynamics could result in different surface heat flux structures within the inner-core regions of TCs.

The continuous advancement of convection into the upshear region is an essential process in TC intensification in directional shear flows (Rappin and Nolan 2012; ON14; Stevens et al. 2014; ON16; Rogers et al. 2016; Munsell et al. 2017; X. Chen et al. 2018). As proposed by GTQ18, low-level upward motion is more likely to be triggered in the downwind region of overall vortex tilt in CW hodographs than in CC hodographs because the low-level vortex tilt is ahead of the overall vortex tilt in the former but behind the overall vortex tilt in the latter. As a result, differences in convection precession in directional shear flows may also originate from the position of low-level vortex tilt relative to the overall vortex tilt. In addition to vortex tilt-dominated dry dynamics, moist convection is important in amplifying the differences in the precession of the tilted vortex, which leads to differences in TC intensification. Using trajectory analyses, ON16 showed that air parcels experiencing larger surface heat fluxes in the upshear region of $\mathrm{CW}$ hodographs can be more easily ingested into the TC core than CC hodographs. As a result, convection can more easily advance into the upshear region in $\mathrm{CW}$ hodographs. In addition to surface heat flux, observations also emphasize the importance of favorable moist environments in the midtroposphere and high sea surface temperatures in supporting persistent deep convection in upshear regions (Rogers et al. 2016; Zawislak et al. 2016).

In the real atmosphere, both dry and moist dynamics are expected to contribute to variations in TC intensification rates in directional shear flows. Frank and Ritchie (1999) found that, in the unidirectional shear, the asymmetric structures are controlled by the dry dynamics in response to the deep-layer shear and boundary layer convergence during the early stage of the simulation and later on are further changed by the moist dynamics. However, little is known about how the dry and moist processes are related and how they collectively affect TC intensity in different directional shear flows. In this study, we combine vortex tilt-dominated dry dynamics and moist processes together to develop a more complete understanding of distinct TC features and propose a pathway that couples various structures to result in the diverse evolution of TCs in directional shear flows. We will demonstrate that convective heating plays an important role in coupling the distinct structures, and that the convective organization determines whether a positive or negative feedback for overall vortex tilt precession and TC intensification is established.

The remainder of this paper is organized as follows. Section 2 describes the numerical model and design of the experiments. Section 3 explains how the dry dynamics couples with moist convection to result in distinct structures in CW and CC hodographs. Section 4 examines the different organization of convection in $\mathrm{CW}$ and $\mathrm{CC}$ hodographs and discusses possible mechanisms. Section 5 presents details of how these structures cooperate together through convective heating to form vortex tilt precessions that are more favorable for TC intensification in CW than in CC hodographs. Moreover, the role of surface heat flux on overall vortex tilt precession is discussed. A comparison of results from this study with other modeling and observational studies is provided in section 6 . Finally, section 7 gives a brief summary of the results.

\section{Model setup and simulation design}

Following the methodology of GTQ18, this study uses the Weather Research and Forecasting (WRF) Model, version 3.4 (WRFv3.4; Skamarock et al. 2008), with the point-downscaling (PDS) method (N11) implemented to investigate vortex evolution in directional shear flows. We use the same domain, initial vortex, boundary conditions, and background directional shear flows as in GTQ18. Most model configurations also follow those of GTQ18 to allow a direct comparison of the results of moist simulations with those of the dry simulations in GTQ18. Readers can refer to GTQ18 for more details of the experiment setup. A two-way nesting is employed in all the simulations. The difference between GTQ18 and the present study is that moist convection is included here. The surface sea temperature is fixed to be $30^{\circ} \mathrm{C}$. The WRF single-moment 6-class microphysics scheme (WSM6; Hong and Lim 2006) is used to simulate microphysical processes including graupel; no cumulus parameterization is applied. The Yonsei University PBL scheme (YSU; Hong et al. 2006) is used to parameterize vertical mixing in the planetary boundary layer. For simplicity, both the longwave and shortwave radiation are turned off. Our simulations do not employ nudging as in ON16 since it is not possible to keep the environmental flow steady in the real atmosphere.

The hodograph of the background directional shear flow is shown in Fig. 1a. Seven control simulations, referred to as CW5, CW2.5, CW1.25, UNIDIR, CC1.25, CC2.5, and CC5, are performed, as in GTQ18. The UNIDIR simulation is a unidirectional shear flow simulation. The numbers represent the amplitude of the cosine function for meridional wind. The environmental $u$ component has a cosine shape with easterly winds of 



FIG. 1. (a) Hodographs of environmental flow in clockwise (CW) and counterclockwise (CC) simulations. The environmental flow begins to rotate at $850 \mathrm{hPa}$ and ceases at $200 \mathrm{hPa}$. The meridional component of environmental flow achieves its maximum magnitude at $\sim 500 \mathrm{hPa}$ in directional shear flows. (b) Time evolution of TC intensity in terms of minimum sea level pressure (hPa). Line colors indicate the simulation: CC5 (red), CC2.5 (brown), CC1.25 (yellow), CW1.25 (light blue), CW2.5 (blue), CW5 (dark blue), and UNDIR (thick black).

$5 \mathrm{~m} \mathrm{~s}^{-1}$ below $850 \mathrm{hPa}$ and a westerly flow of $5 \mathrm{~m} \mathrm{~s}^{-1}$ above $200 \mathrm{hPa}$ in all the simulations. Therefore, the deep-layer shear between 200 and $850 \mathrm{hPa}$ in all the simulations corresponds to a $10 \mathrm{~m} \mathrm{~s}^{-1}$ westerly shear flow.

In addition to these simulations, two sets of sensitivity experiments are conducted based on the simulation CW2.5. In the first set of sensitivity simulations, convective heating is suppressed to investigate its role in vortex tilt precession. In these simulations, labeled CW2.5_0.5DH and CW2.5_0DH, the amplitudes of latent heating in the microphysical processes are modified at each time step to be 0.5 and 0 times the original values before updating the temperature, respectively. In the second set of sensitivity experiments, labeled CW2.5_ 0.5MSF and CW2.5_0MSF, the strong surface heat flux (latent heat flux plus sensible heat flux) is removed at each time step to examine its role in the precession of vortex tilt into the upshear region. In CW2.5_0.5MSF, surface heat fluxes that are larger than half the maximum value across the domain are set to zero. The maximum value is calculated within the innermost domain at every time step. As strong surface heat fluxes are primarily located in the downstream region of convection (see section 3 and Fig. 4), this sensitivity simulation only removes strong heat fluxes that are near the downwind region of convection clusters. In CW2.5 0MSF, all surface heat fluxes across the inner domain are removed. The suppression of convective heating and removal of strong surface heat fluxes are only applied across the innermost domain and between hours 15 and 25 , during which the differences in the precession of overall vortex tilt lead to various TC intensification rates in CW and CC hodographs.

\section{Imprint of dry dynamics in the moist simulations}

The evolution of TC intensity in all the control simulations is similar during the first $20 \mathrm{~h}$ (Fig. 1b). After hour 20, the TCs in the CW and UNIDIR hodographs begin to intensify rapidly, whereas TCs have a much slower intensification rate in $\mathrm{CC} 1.25$ and $\mathrm{CC} 2.5$ and undergo no intensification in CC5. This is consistent with previous studies (N11; ON14; ON16), which found that CW hodographs are more favorable for TC intensification than CC hodographs. Structural differences and physical processes that occur around hour 20 are critical for various TC intensification rates. In the following section, two periods (from hours 15 to 20 and from hours 20 to 25) during TC development are discussed in detail.

The evolution of overall vortex tilt before hour 15 confirms the importance of dry dynamics, as identified by GTQ18 (Fig. 2). Vortex centers are calculated as the vorticity centroid within a radius of $200 \mathrm{~km}$ from the location of minimum pressure at each level. At early stages (before hour 15), the magnitudes of overall vortex tilt all increase and do not differ significantly regardless of whether the directional shear flow rotates clockwise or counterclockwise (Fig. 2a). However, overall vortex tilts in $\mathrm{CW}$ hodographs are directed toward the downshear-left region, compared with downshear and downshear-right regions in CC hodographs (Fig. 2b). These features are consistent with the results of GTQ18, which did not consider moist convection.

Differences in the distributions of convection within TCs in CW and CC hodographs exist prior to the development of differences in TC intensity (Fig. 3). At hour 15 , convective clusters in $\mathrm{CW}$ hodographs are located in the downshear-left (CW1.25 and CW2.5) or left-of-shear 

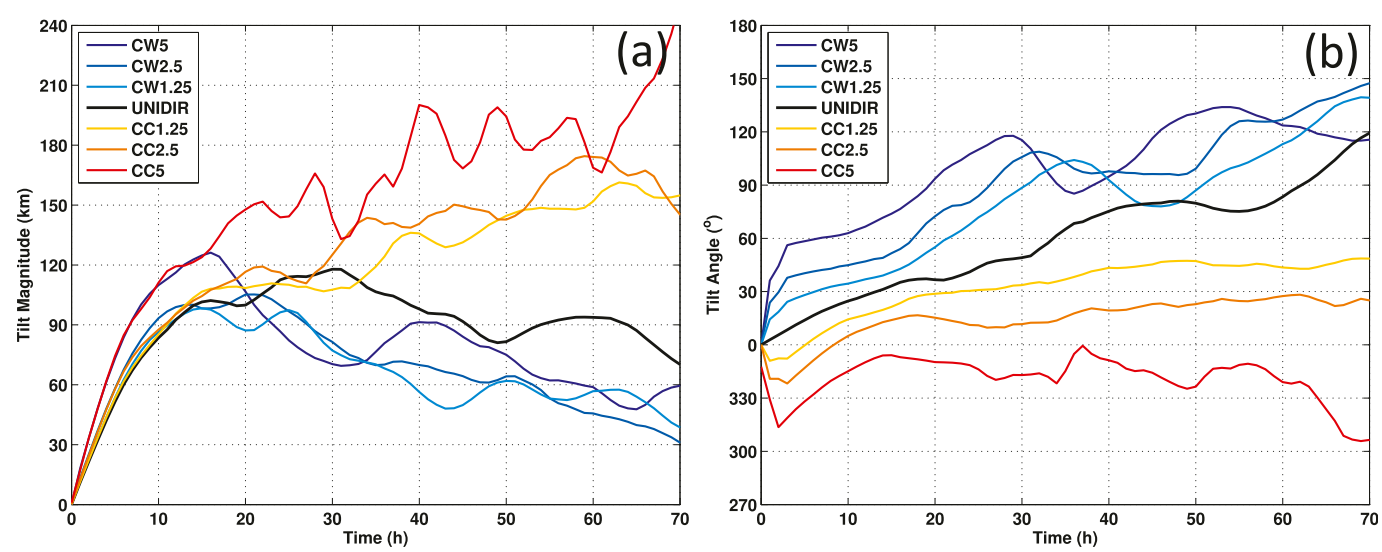

FIG. 2. Time evolution of (a) overall vortex tilt $(0-8 \mathrm{~km})$ magnitude $(\mathrm{km})$ and $(\mathrm{b})$ tilt angle $\left({ }^{\circ}\right)$. The vortex center at each level is calculated as the vorticity centroid within a radius of $200 \mathrm{~km}$ from the location of minimum pressure. The tilt angle is calculated counterclockwise from east (i.e., $0^{\circ}$ for east, $90^{\circ}$ for north, $180^{\circ}$ for west, $270^{\circ}$ for south). Deep-layer vertical wind shear is directed to the east. Line colors indicate the simulation: CC5 (red), CC2.5 (brown), CC1.25 (yellow), CW1.25 (light blue), CW2.5 (blue), CW5 (dark blue), and UNDIR (thick black).

(CW5) regions (Figs. 3a-c), whereas those in CC hodographs are concentrated in the downshear-right region (Figs. 3d-f). The locations of convective clusters are generally in phase with the direction of overall vortex tilt. In contrast to ON14, no obvious displacement of local positive helicity from convection is found in our simulations (Fig. 3). Actually, the convection is also generally in phase with local positive helicity in ON14 (Fig. 9 in ON14). It is a direct manifestation of dry dynamics that upward motions are a balanced response to vortex tilt and are generally collocated with positive local helicity (GTQ18). In response to the vortex tilt, the isentropic surface must be distorted in the down-tilt direction and upward motion must occur to the right-oftilt side along the isentropic surface. At the same time, the wind direction changes in a clockwise sense to the right-of-tilt side and thus the positive helicity is collocated with convection in the moist simulation. Theoretical studies show that the positive helicity indicates warm advection (Tan and Wu 1994) in the adiabatic flow and thus the vertical motion is proportional to the local helicity (Hide 2002). This also indicates the collocation of local helicity and convection. A detailed investigation shows that more convection is located ahead of the overall vortex tilt in $\mathrm{CW}$ hodographs than in CC hodographs. This is because the low-level vortex tilt in CW hodographs has a different configuration with respect to the overall vortex tilt than does that in CC hodographs, as explained by GTQ18. In CW5, low-level vortex tilt $(2-5 \mathrm{~km})$ is closer to the upshear region than the overall vortex tilt (Fig. 3c), but is closer to the right-of-shear region than the overall vortex tilt in CC5 (Fig. 3f). As a result of balanced dynamics, stronger upward motion occurs at low levels, leading to convection clusters that are ahead of the overall vortex tilt in CW5 hodographs. There are no obvious differences between overall vortex tilt and low-level vortex tilt in the other cases (Figs. 3a,b,d,e). This is due to the enhanced coupling between vortex centers at different levels from the feedback of moist convection, and also the smaller curvature in directional shear flow than in CW5 and CC5.

Although the vortex tilt affects the location of convection during the early stage of TC development, it alone cannot capture all observed differences, such as the configuration of surface heat flux, which has been shown to be important for the precession of convection in directional shear flows (ON16). Figure 4 shows that strong surface heat flux (the sum of sensible and latent heat fluxes) is generally located between the upshearleft region in CW2.5 and CW5 (Figs. 4b,c) and the leftof-shear region in CW1.25 (Fig. 4a), but is concentrated in the downshear-left region in $\mathrm{CC} 1.25$ and $\mathrm{CC} 2.5$ (Figs. 4d,e) and the downshear region in CC5 (Fig. 4f). The preference of strong surface heat fluxes to be located near the left-of-shear region can be explained by stronger surface wind speeds in this region due to the superposition of low-level flow with cyclonic circulation, as low-level environmental winds come from the east in all the simulations. In addition, the evolution of lowlevel winds in shear flows is also quadrant dependent with stronger winds in the left-of-shear region ( $\mathrm{Gu}$ et al. 2016). The relative locations of strong surface heat fluxes are consistent with the results of ON16. However, the strength of the surface heat flux at hour 15 in $\mathrm{CW}$ hodographs is weaker than that in CC hodographs. This is in contrast with ON16, who found that the surface heat flux is stronger in $\mathrm{CW}$ hodographs than in $\mathrm{CC}$ hodographs before differences in TC intensification 

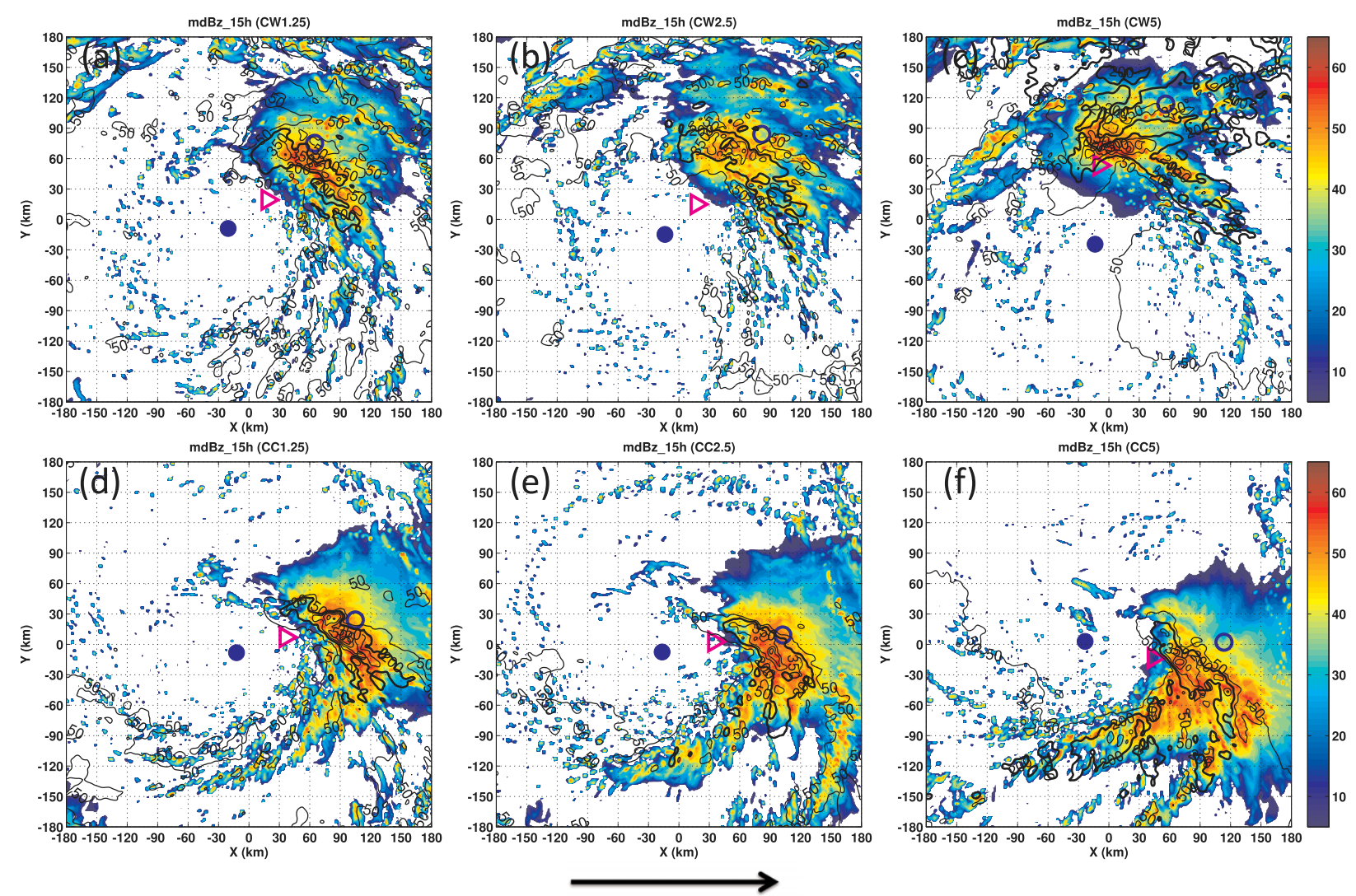

FIG. 3. Plan view of maximum reflectivity (dBZ; shaded) and local helicity (black contours at 50, 200,350 $\mathrm{m} \mathrm{s}^{-2}$ ) at hour 15: (a) CW1.25, (b) CW2.5, (c) CW5, (d) CC1.25, (e) CC2.5, and (f) CC5. The black shaded circle, magenta triangle, and black hollow circle represent the vortex centers at 2-, 5-, and 8-km height, respectively. Black contours represent the local helicity. The contour of $200 \mathrm{~m} \mathrm{~s}^{-2}$ is highlighted with thick black lines. The thick black arrow at the bottom of the figure indicates the direction of deep-layer shear.

rates develop. Because the surface heat flux does not solely depend on the surface wind speed, it is also necessary to investigate the structure of thermodynamic disequilibrium, as the surface heat flux is the product of these two factors. Figure 4 shows that low equivalent potential temperatures generally overlap with strong surface heat flux. By examining a composite vertical cross section along the line of strong surface heat flux and convection (not shown), we find that precipitation downdrafts that originate from convection bring midlevel low-entropy air into the boundary layer, building a cold reservoir and a region of large thermodynamic disequilibrium, resulting in strong surface heat fluxes in the downstream region of convective clusters in both $\mathrm{CW}$ and $\mathrm{CC}$ hodographs. Therefore, the stronger surface heat fluxes in CC hodographs before the intensification rates differ are primarily due to the greater cold pool strength, which is further related with the strength of convection. During 15-20h, the low-entropy downdrafts are stronger in CC hodographs than in $\mathrm{CW}$ hodographs (not shown). The relative strength of surface heat fluxes between $\mathrm{CW}$ and $\mathrm{CC}$ hodographs will change during later hours, depending on the strength of convection within the inner-core region (see section 4). It is not clear why the convective strength are different in CC and $\mathrm{CW}$ hodographs during different time periods and deserves more detailed investigation in the future. Please note that the comparison of surface heat fluxes between our study and ON16 is not direct because they are during different hours of the simulation. However, the comparison period in this study (15-20h) and ON16 (24-36h) is generally during the same stage of the TC evolution; that is, a period just before and after the intensification rates become different, and therefore the comparison is reasonable. In addition, this study uses the total heat flux, while ON16 just examine the latent heat flux. Detailed investigation of sensible and latent heat flux individually gives the same conclusion as the total heat flux.

\section{Convection organization in directional shear flows}

Although balanced dynamics control the azimuthal position of convection during the early stage of development, 

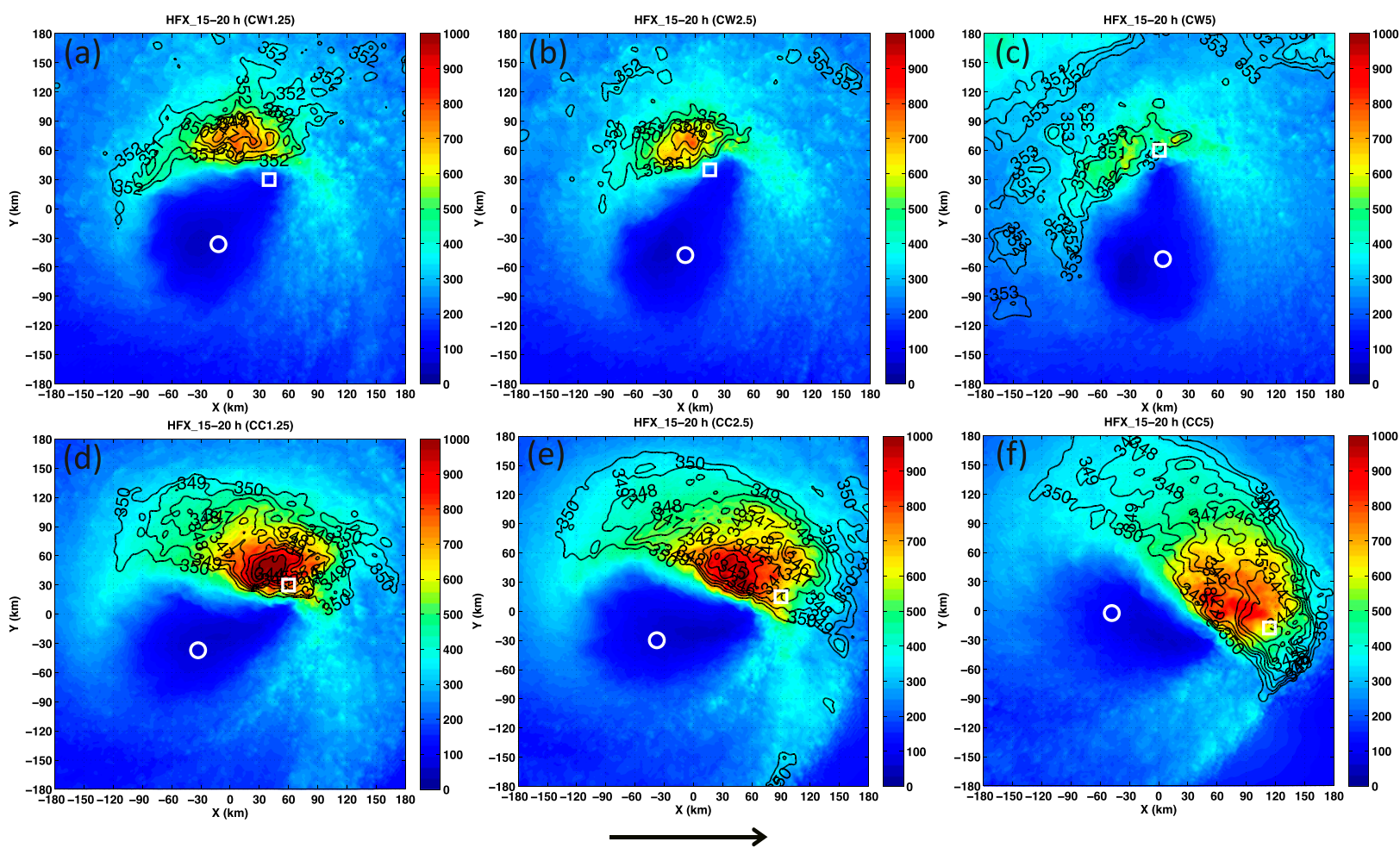

FIG. 4. Plan view of time-averaged (hours 15-20) surface heat flux (sum of latent heat flux and sensible heat flux; shading; W $\mathrm{m}^{-2}$ ) and equivalent potential temperature (black contours; K) at the surface: (a) CW1.25, (b) CW2.5, (c) CW5, (d) CC1.25, (e) CC2.5, and (f) CC5 The white circle and white square represent the vortex centers at 2- and 8-km height at hour 20, respectively. The thick black arrow at the bottom of the figure indicates the direction of deep-layer shear.

they cannot explain all the features of convection organization in $\mathrm{CW}$ and $\mathrm{CC}$ hodographs at later times (hours 15-30), when differences in the magnitude and precession of the overall vortex tilts (Fig. 2) and the intensification rates (Fig. 1) begin to develop. Figures 5 and 6 show the time-averaged distribution of simulated radar reflectivity during hours $15-20,20-25$, and 25-30 for CW and CC hodographs, respectively. In CW hodographs during hours $15-20$, the convection is located in the downshear-left region in CW1.25 and CW2.5 (Figs. 5a,d) and near the left-of-shear region in CW5 (Fig. 5g). Between hours 20 and 25, the leading edge of the convective cluster in CW5 (Fig. 5h) advances into the upshear-left region, whereas the front edges of the convective clusters in CW1.25 and CW2.5 (Figs. 5b,e) move into the left-of-shear region. After hour 25, all convection in $\mathrm{CW}$ hodographs has moved into the upshear region (Figs. 5c,f,i). Therefore, although the tail of the convective cluster remains in the downshear region, the leading edge of the convective cluster tends to organize near the left-of-shear and upshear-left regions, and thus helps advance the overall vortex tilt into the upshear region (Fig. 5). In contrast, in CC hodographs the leading edge of the convective cluster remains in the downshear region but the convection tends to develop a tail structure extending from the main cluster in the downshear region to the right-of-shear region (Figs. 3d-f and 6).

Furthermore, convection is organized quite differently in the radial direction between the two types of hodographs. In CW hodographs, the convection is confined within $120-\mathrm{km}$ radius and is generally organized along the azimuth (Fig. 5). In CC hodographs, in addition to the main convective cluster in the inner region, there are indications of convection organization radially outward (150 km; Fig. 6). From hours 15 to 20 (Fig. 6a), the main convective cluster in $\mathrm{CC} 1.25$ is located in the downshear region. At the same time, weak signals of organized convection are established radially outward. After $5 \mathrm{~h}$ (hours 20-25; Fig. 6b), the outer convection intensifies as the inner-core convection weakens slightly. The resulting distribution of convection exhibits a radially elongated pattern. Later, during hours 25-30, the inner convection weakens noticeably. As a result, the overall convection is located at larger radial distances (Fig. 6c). Similar organization also occurs in the CC2.5 and CC5. In CC2.5, the outer convection is initially organized in a spiral line along the azimuth during hours 

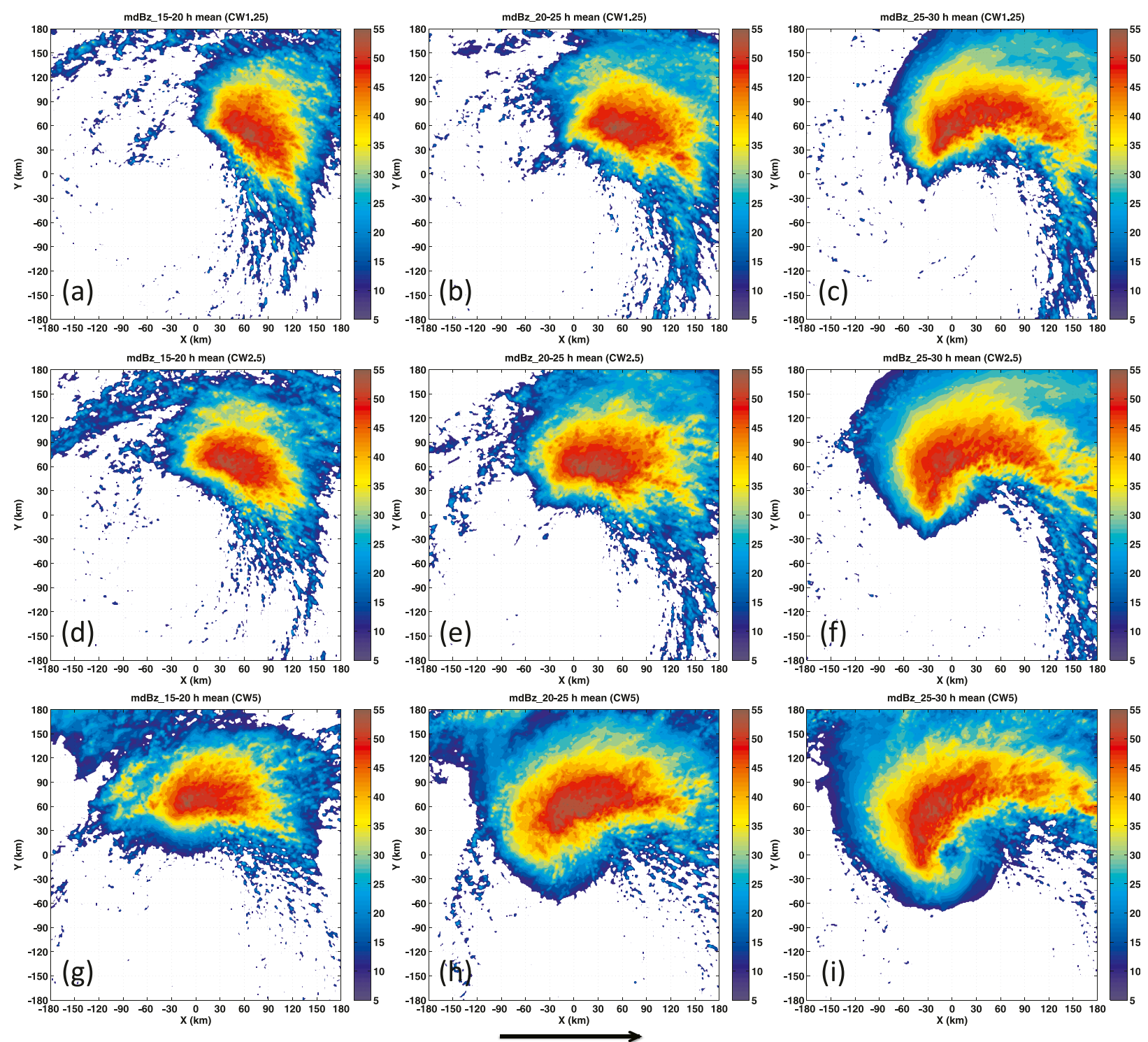

FIG. 5. Plan view of time-averaged reflectivity $(\mathrm{dBZ})$ in the innermost domain in simulations with CW hodographs: (a)-(c) CW1.25, (d)-(f) CW2.5, and (g)-(i) CW5. The averaging period is hours (left) 15-20, (center) 20-25, and (right) 25-30. The thick black arrow at the bottom of the figure indicates the direction of deep-layer shear.

15-20 (Fig. 6d), and later (hours 20-25) intensifies as it merges with the weakening convection in the inner region, resulting in a rainband along the radial direction (Fig. 6e). Finally, during hours $25-30$, the overall convection weakens and shifts to cover a more radially outward region (Fig. 6f). In CC5 during hours 15-20, the outer convection has already merged with the inner-core convection, covering a large area in the downshear-right quadrant (Fig. 6g). Later (hours 20-25), the outer convection maintains its strength and location as the inner convection weakens (Fig. 6h). Consequently, the remaining convection is concentrated in the outer region in the downshear-right quadrant (Fig. 6i).
To investigate the mechanism of convection organization, the vertical acceleration is decomposed into buoyancy and dynamic forcings (Jeevanjee and Romps 2015). The relative roles of these two forcing could be quantified by diagnosing the vertical buoyancy acceleration $a_{b}$ and the vertical inertial acceleration $a_{i}$. These two accelerations could be calculated by solving the Poisson equation for $a_{b}$ and $a_{i}$ :

$$
\begin{aligned}
& -\nabla^{2}\left(\bar{\rho} a_{b}\right)=g \nabla_{h}^{2} \rho, \\
& -\nabla^{2}\left(\bar{\rho} a_{i}\right)=-\partial_{z} \nabla \cdot[\bar{\rho}(\mathrm{u} \cdot \nabla) \mathrm{u}],
\end{aligned}
$$



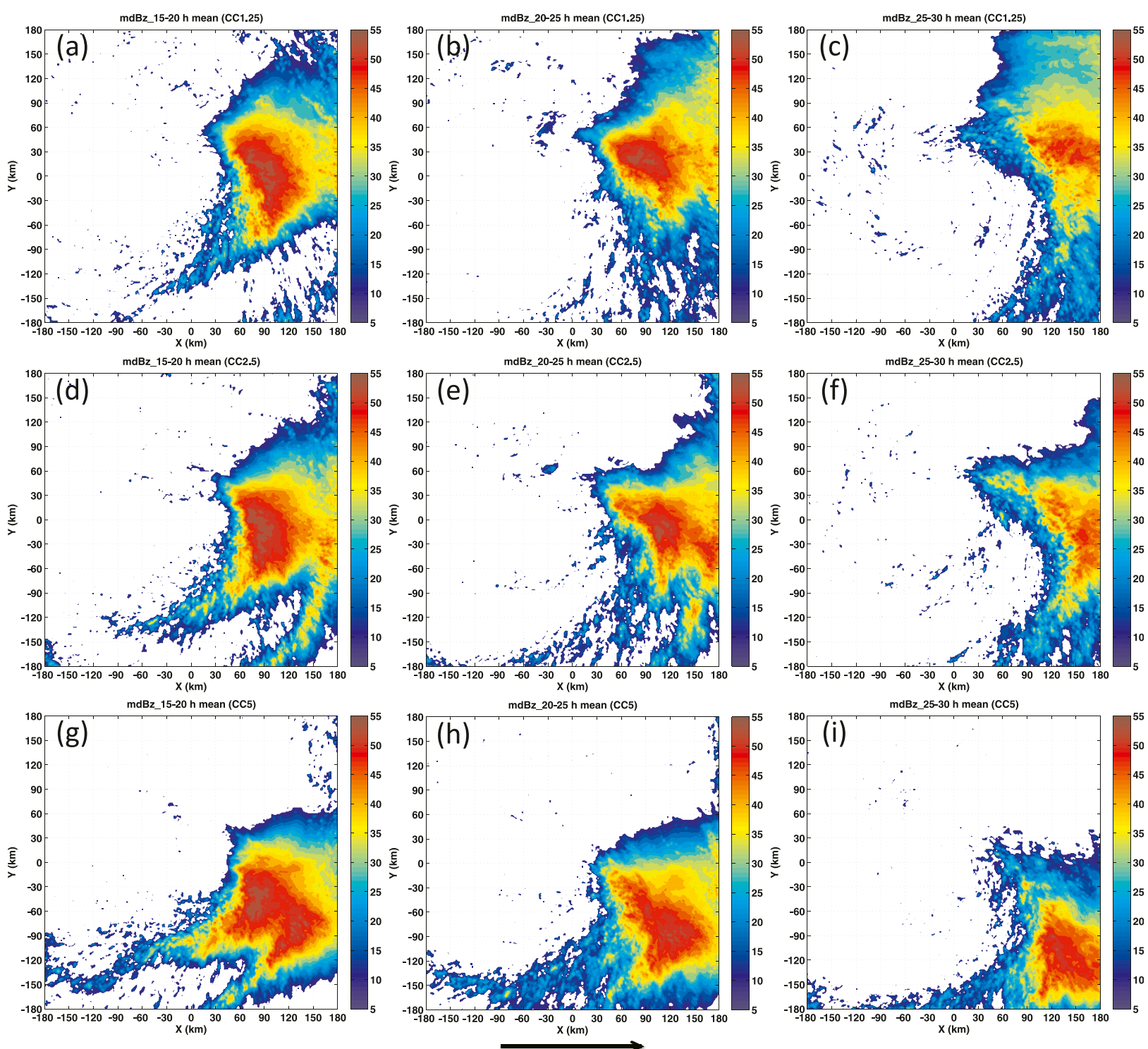

FIG. 6. Plan view of time-averaged reflectivity (dBZ) in the innermost domain in simulations with CC hodographs: (a)-(c) CC1.25, (d)-(f) CC2.5, and (g)-(i) CC5. The averaging period is hours (left) 15-20, (center) 20-25, and (right) 25-30. The thick black arrow at the bottom of the figure indicates the direction of deep-layer shear.

where $\mathbf{u}$ is the three-dimensional wind vector, $g$ is the gravitational acceleration, $\rho$ is air density, $\bar{\rho}$ is the reference density, $\nabla^{2}$ is the three-dimensional Laplacian, $\nabla_{h}^{2}$ is the horizontal Laplacian, and $\nabla$. is the threedimensional divergence operator. Figure 7 shows the total vertical acceleration (Figs. 7c,f), its dynamic component (Figs. 7a,d), and its thermodynamic component (Figs. 7b,e) below $1.5 \mathrm{~km}$ during hours 19-20 for CW2.5 (Figs. 7a-c) and CC2.5 (Figs. 7d-f). The dynamic forcing outweighs the thermodynamic forcing in both CW2.5 and CC2.5. This is also the case generally during hours 15-30 and in other simulations (including the sensitivity experiments following the deactivation of diabatic heating and surface heat fluxes, not shown) and therefore suggests that the surface heat flux may not play a direct role in convection organization. In addition, the surface convergence does not coincide well with the strong surface heat fluxes during hours 15-25 (not shown). Therefore, the strong heat flux does not appear to feedback directly to assist the continuous advancement of convection into the upshear side. However, in CW hodographs, the strong heat flux does begin to overlap with surface convergence once the overall vortex tilt precesses into the upshear side, favoring subsequent rapid intensification. 



FIG. 7. Plan view of the decomposition of vertical acceleration near surface (0-0.5 km) in simulations (a)-(c) CW2.5 and (d)-(f) CC2.5 during hours 19-20: (a),(d) inertial vertical acceleration $\left(\mathrm{m} \mathrm{s}^{-2}\right)$; (b), (e) effective buoyancy acceleration ( $\left.\mathrm{m} \mathrm{s}^{-2}\right)$; and (c),(f) total vertical acceleration $\left(\mathrm{m} \mathrm{s}^{-2}\right)$. Black contours (from 1 to $4 \mathrm{~m} \mathrm{~s}^{-1}$ with a $1 \mathrm{~m} \mathrm{~s}^{-1}$ interval) indicate vertical motion. The domain is chosen to ensure that the convection is near the center of each plot.

There are several possible dynamic mechanisms of convection organization in directional shear flows. One involves kinematic structural changes in response to vortex tilt, which has its roots in dry dynamics, as described by GTQ18, and is partly responsible for differences in the azimuthal location of convection. Another is related to storm movement. A northward component of TC movement exists in CW hodographs, but a southward component exists in CC hodographs. This results in different structures of asymmetric radial inflows (see Fig. 8 in GTQ18). Figure 8 shows the distribution of radial flows within the boundary layer $(0-1.5 \mathrm{~km})$ over $15-25 \mathrm{~h}$. In CW hodographs, the strongest inflow is located in the left-of-shear side. The radial inflows tend to occur in the upshear-left quadrant in CW2.5 and CW5 simulations and lead the strong upward motions. This corresponds to the continuous organization of convection on the left-of-shear side in CW hodographs. In CC hodographs, a large part of the radial inflows come from the right-of-shear side. The stronger the southward environmental flow $(\mathrm{CC} 5>\mathrm{CC} 2.5>\mathrm{CC} 1.25)$ is, the stronger the radial inflow on the right-of-shear side because the southward movement is stronger because of the enhanced vertically averaged steering flow. Therefore, the different asymmetric structures of boundary layer inflows may be responsible for the long tail in the rightof-shear region in CC hodographs, and favors further extension of the leading edge of convection into the left-of-shear region in CW hodographs. Finally, the mechanism proposed by Riemer (2016) may support convection organization in the radial direction outside the eyewall in CC hodographs. The overlap of asymmetric frictional convergence due to vortex tilt and lowlevel high-entropy air associated with the deformed moist envelope may favor deep convection in the downshear-right region. Cold pool dynamics are an alternative mechanism that may explain TC convection organization (e.g., Davis 2015). However, a detailed examination indicates that cold pools associated with convection are not in an optimal configuration with respect to local vertical wind shear along the azimuthal direction. The weakening of cyclonic circulation with height (not shown) due to the baroclinic nature of TCs leads to a horizontal vorticity that has the same sign as the baroclinically generated horizontal vorticity because of the cold pool. This does not support upright convection and thus is not favorable for convective organization azimuthally (Rotunno et al. 1988). The relative 

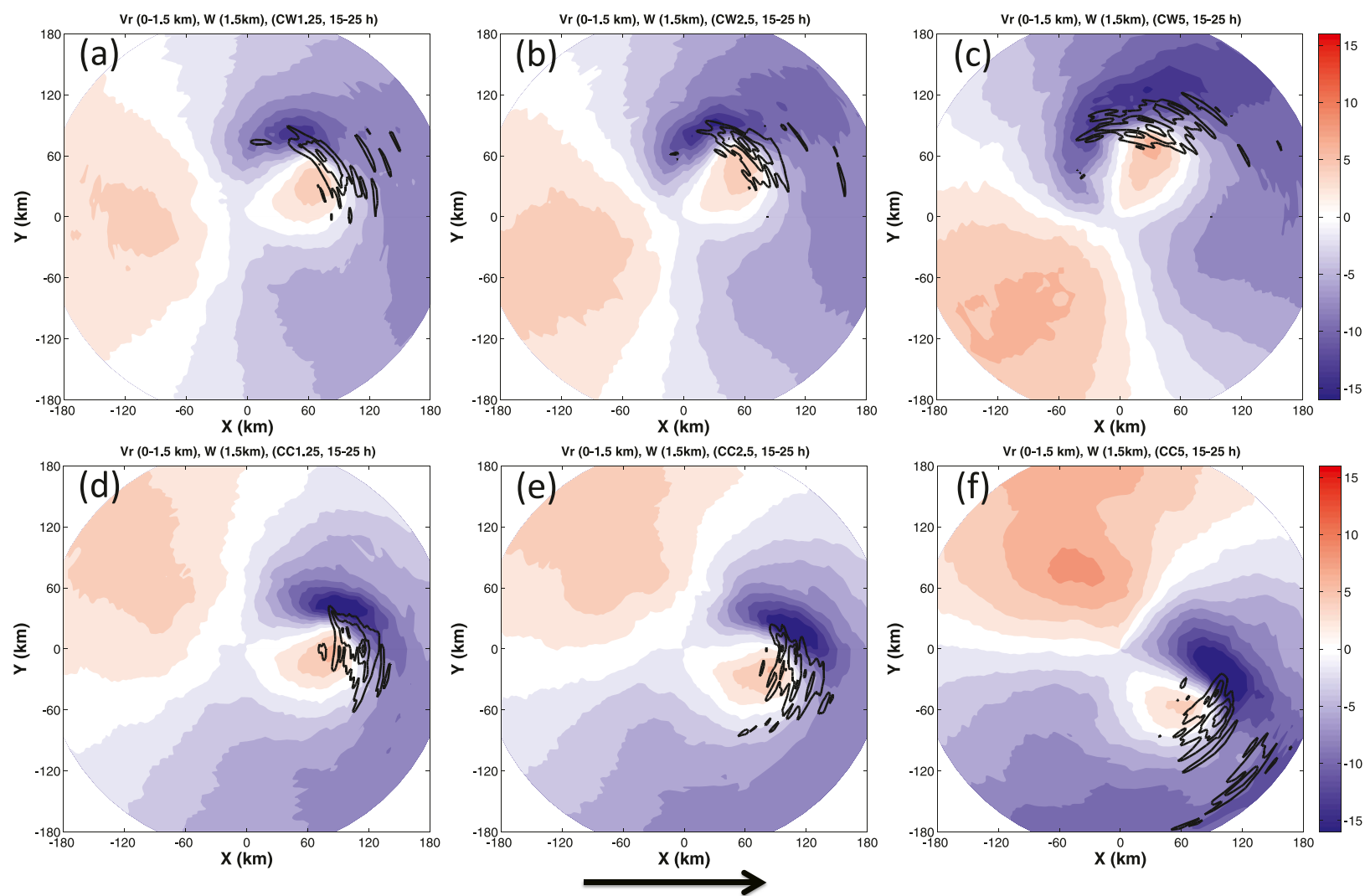

FIG. 8. Plan view of time-averaged $(15-25 \mathrm{~h})$ radial velocity (shading; $\mathrm{m} \mathrm{s}^{-1}$ ) within the boundary layer $(0-1.5 \mathrm{~km})$ and time-averaged (15-25 h) positive vertical velocity (contours; every $0.5 \mathrm{~m} \mathrm{~s}^{-1}$ starting from $0.5 \mathrm{~m} \mathrm{~s}^{-1}$ ): (a) CW1.25, (b) CW2.5, (c) CW5, (d) CC1.25, (e) CC2.5, and (f) CC5. The thick black arrow at the bottom of the figure indicates the direction of deep-layer shear.

contributions of these possible mechanisms is not easy to distinguish because it is difficult to further decompose the dynamic forcing into different components associated with these mechanism and thus will be left for a future study.

Differences in convection organization between $\mathrm{CW}$ and CC hodographs result in different midtroposphere humidity and surface heat fluxes in the downwind region of overall vortex tilt. Figure 9 shows the time evolution of relative humidity in the midtroposphere (4-8 km) for azimuth angles of $30^{\circ}-60^{\circ}$ in the downstream region from the overall vortex tilt within an annular region of $30-150 \mathrm{~km}$ from the TC center. Although the relative humidity in all the directional shear flows is similar for the first $15 \mathrm{~h}$, it increases continuously to $90 \%$ until hour 30 in CW hodographs, whereas in CC hodographs it begins to decrease from hours 15 to 20 with a drier downstream environment when the intensification occurs. This is because of differing convection organization in the azimuth due to TC movement and the relative configuration of the low-level vortex tilt with respect to the overall vortex tilt. An alternative explanation might be related with the midlevel advection. In the
CW hodographs, the southerly environmental mean flow may advect the moist envelop to the downwind region of overall vortex tilt, resulting in a moist midtroposphere. In the CC hodographs, the moist envelop is more easily advected to the right of overall vortex tilt because of the northerly environmental mean flow, leaving a drier midtroposphere in the downwind region of overall vortex tilt. Surface heat flux also presents contrasting features in directional shear flows. Figure 10 shows that the surface heat flux in CW hodographs (Figs. 10a-c) is much stronger than that in CC hodographs (Figs. 10d-f) during hours $25-30$. This is because the convection at small radii is weaker because of the continuous organization of convection radially outward along with lowentropy downdrafts located in a region with lower wind speeds in CC hodographs.

$\mathrm{Gu}$ et al. (2015) showed that shear-induced convection outside the eyewall can transport moisture upward above the boundary layer, thus reducing the radial gradient of moist entropy and decreasing the output work of TC heat engine, and potentially weakening the TC during its mature stage. Figure 11 shows the time evolution of azimuthally averaged moist entropy in the 


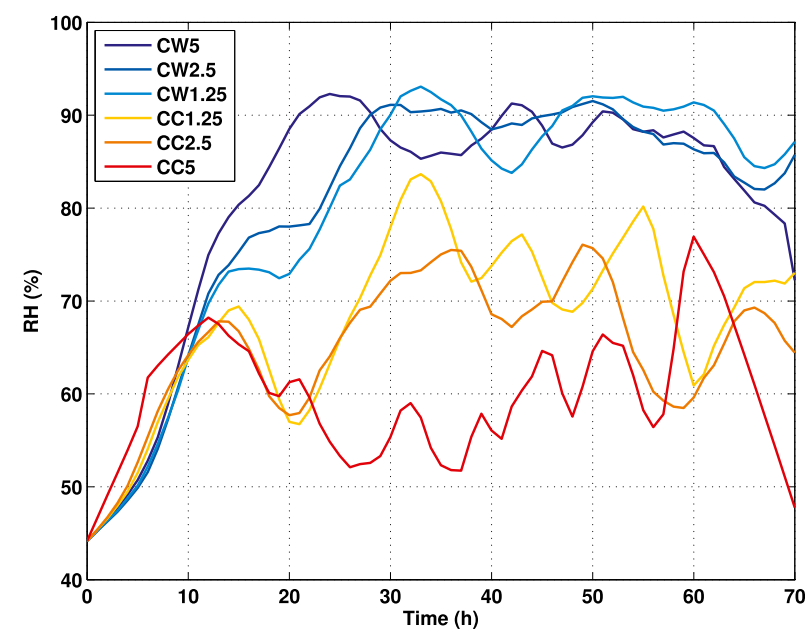

FIG. 9. Time evolution of relative humidity averaged over the midtroposphere $(4-8 \mathrm{~km})$ for azimuth angles of $30^{\circ}-60^{\circ}$ in the downstream region of overall vortex tilt and within a radius of $30-150 \mathrm{~km}$ from the vortex center at a $2-\mathrm{km}$ height in simulations of directional shear flows. Line colors indicate the simulation: CC5 (red), CC2.5 (brown), CC1.25 (yellow), CW1.25 (light blue), CW2.5 (blue), and CW5 (dark blue).

inner $(0-80 \mathrm{~km})$ and outer $(100-180 \mathrm{~km})$ regions, and the difference between these two regions. The moist entropy difference between the inner and outer regions in $\mathrm{CW}$ hodographs is larger than that in CC hodographs throughout the simulated TC lifetime. During hours 20-30, the moist entropy in the inner region in $\mathrm{CC} 1.25$ and $\mathrm{CC} 2.5$ increases more rapidly $\left(>5 \mathrm{~J} \mathrm{~kg}^{-1} \mathrm{~K}^{-1}\right)$ than in $\mathrm{CW}$ cases $\left(<5 \mathrm{~J} \mathrm{~kg}^{-1} \mathrm{~K}^{-1} ;\right.$ Fig. 11a). However, the moist entropy in the outer region in $\mathrm{CC} 1.25$ and $\mathrm{CC} 2.5$ also increases $\left(>5 \mathrm{~J} \mathrm{~kg}^{-1} \mathrm{~K}^{-1}\right)$ more rapidly than in CW hodographs (nearly constant; Fig. 11b), and thus results in a weaker moist entropy difference between the inner and outer regions in CC1.25 and CC2.5 than in CW hodographs (Fig. 11c). Although the radial gradient of moist entropy increases in $\mathrm{CC} 1.25$ and $\mathrm{CC} 2.5$, rapid increases are inhibited by the continuous organization of convection at outer radii. In $\mathrm{CC} 5$, convection within the inner region is effectively weakened by a more intense organization of convection in the outer region (Figs. $6 \mathrm{~g}-\mathrm{i}$ ) and also results in a weaker increase in the radial gradient of moist entropy than in CW hodographs (Figs. 11a,c). As a result, in CC hodographs the convection in the outer region prevents the radial gradient of moist entropy from increasing rapidly and thus may inhibit TC intensification. This is consistent with the importance of shear-induced outer convection in changing the radial gradient of moist entropy and thus TC intensity, although here we focus on the early stage rather than the mature stage of TC development.

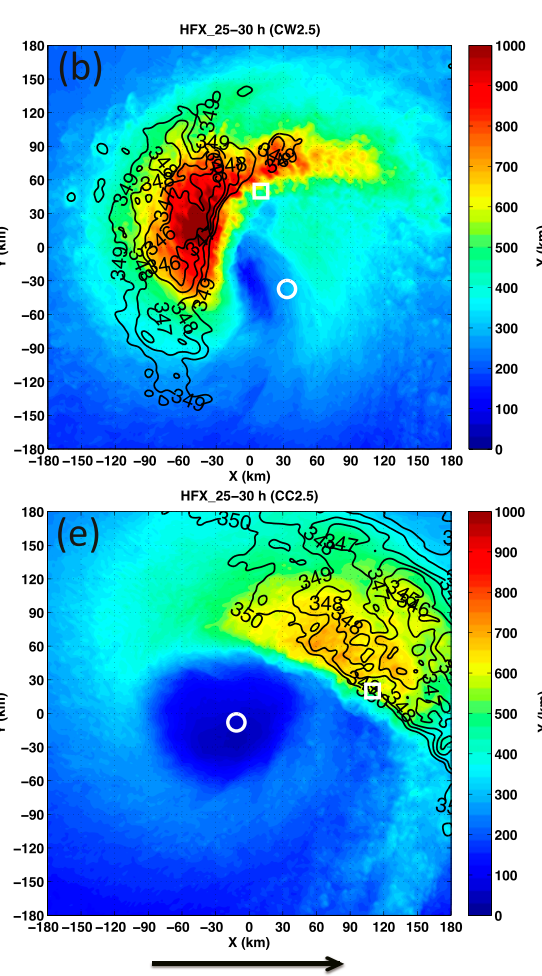
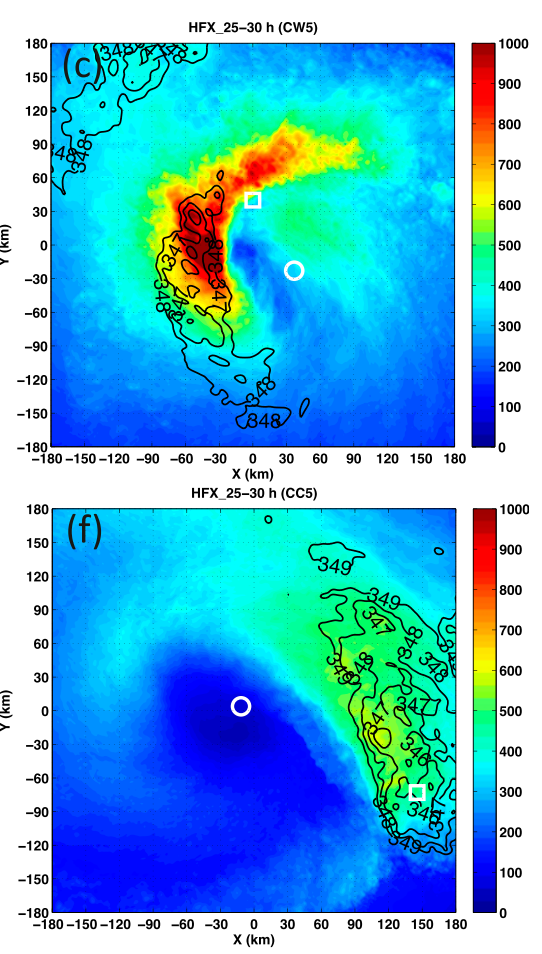

FIG. 10. As in Fig. 4, but for time-averaged surface heat flux (sum of latent heat flux and sensible heat flux; $\mathrm{W} \mathrm{m}^{-2}$ ) during hours $25-30$. The white circle and white square represent the vortex centers at heights of 2 and $8 \mathrm{~km}$ at hour 30, respectively. 

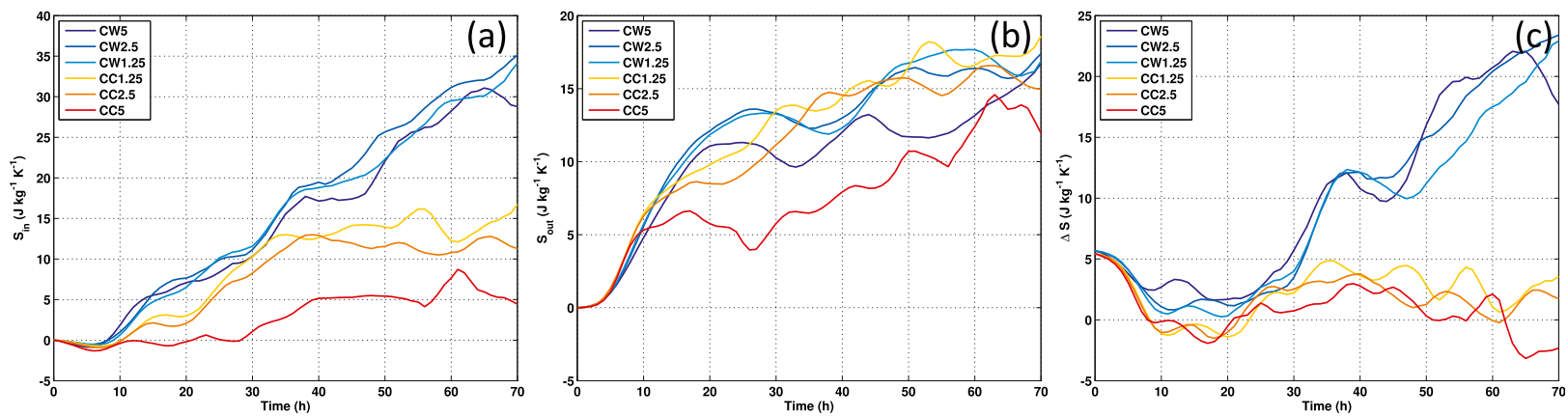

FIG. 11. Time evolution of azimuthally averaged moist entropy and moist entropy difference between the inner-and outer-core regions over 4-8-km height: (a) moist entropy in the inner region $(0-80 \mathrm{~km})$, (b) moist entropy in the outer region (100-180 km), and (c) moist entropy difference between the inner and outer regions. Line colors indicate the simulation: CC5 (red), CC2.5 (brown), CC1.25 (yellow), CW1.25 (light blue), CW2.5 (blue), and CW5 (dark blue).

Differences in convection organization lead to distinct dynamic structures, in addition to thermodynamic structures. Figure 12 shows the radial distribution of azimuthally averaged potential vorticity (PV) at heights of $2-5 \mathrm{~km}$ during hours $20-25$. The TCs in CC hodographs have smaller PV in the inner region and larger $\mathrm{PV}$ in the outer region than in CW hodographs. This is because continuous organization of convection radially outward in CC hodographs redistributes the PV through convective heating and also generates PV through vortex stretching, resulting in a broader PV skirt with smaller negative radial gradients than in $\mathrm{CW}$ hodographs. Theoretical studies (Schecter et al. 2002; Reasor et al. 2004) have shown that TCs with larger magnitudes of the negative radial gradient of the PV skirt are more resilient in shear flows. This suggests that tilted TCs in CC hodographs are more likely to be further tilted away by shear flows, thus reducing the precession rate.

\section{Roles of convective heating in vortex precession}

As described in the last two sections, dry dynamics and other processes (e.g., TC movement) set up distinct organizations of convection that result in quite different dynamic (PV skirt) and thermodynamic (downwind midtroposphere relative humidity, surface heat flux and radial gradient of moist entropy within inner-core region) structures in directional shear flows. A critical issue is how these structural differences couple to affect the overall vortex tilt and $\mathrm{TC}$ intensification rates.

An important component of moist convection is latent heat release, whose role can be investigated by directly comparing moist simulations with the dry simulations of GTQ18, as they used the same experimental and model setups except for the inclusion of moist convection. Figure 13 shows the time evolution of overall vortex tilt in terms of magnitude and direction for both moist and dry simulations. Convective heating has two effects on the evolution of vortex tilt. The first is that convective heating aids the coupling between vortices at different levels, and thus prevents further departures of upperlevel vortices from low-level vortices. Moist convection begins to take effect before hour 10 and tends to reduce the vortex tilt in both $\mathrm{CW}$ and $\mathrm{CC}$ hodographs (Figs. 13a,b). Although the magnitude of the vortex tilt decreases after the vortex tilt precesses into the upshear region, the timing of its decrease is generally ahead of the timing of the upshear precession in CW hodographs (Figs. 13a,c). This indicates that convective heating first aids the coupling between low-level and upper-level

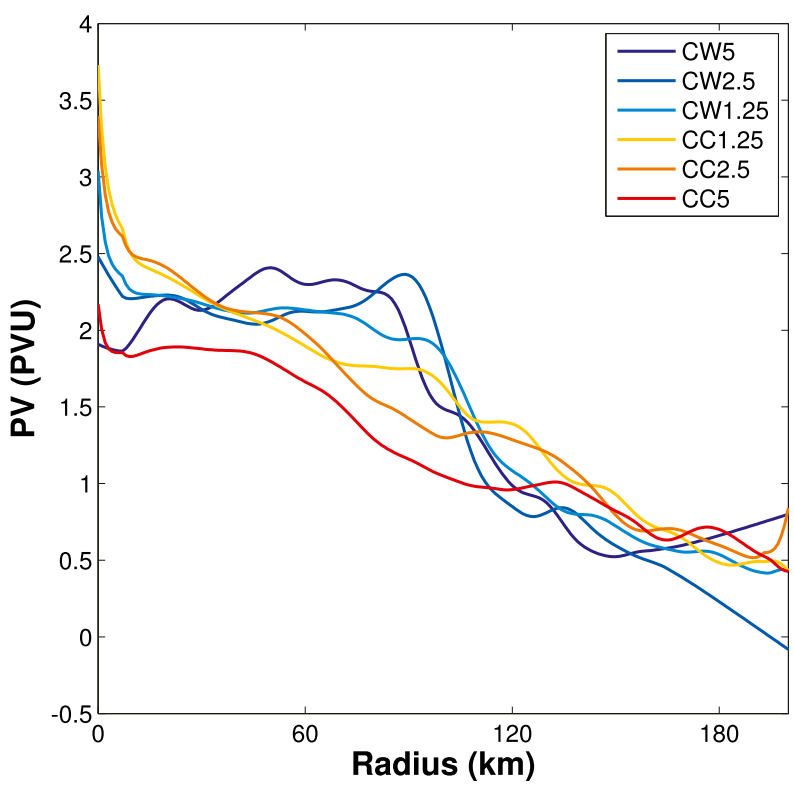

FIG. 12. Radial profile of azimuthally, vertically $(2-5 \mathrm{~km})$, and time-averaged $(20-25 \mathrm{~h}) \mathrm{PV}$. Line colors indicate the simulation: CC5 (red), CC2.5 (brown), CC1.25 (yellow), CW1.25 (light blue), CW2.5 (blue), and CW5 (dark blue). 

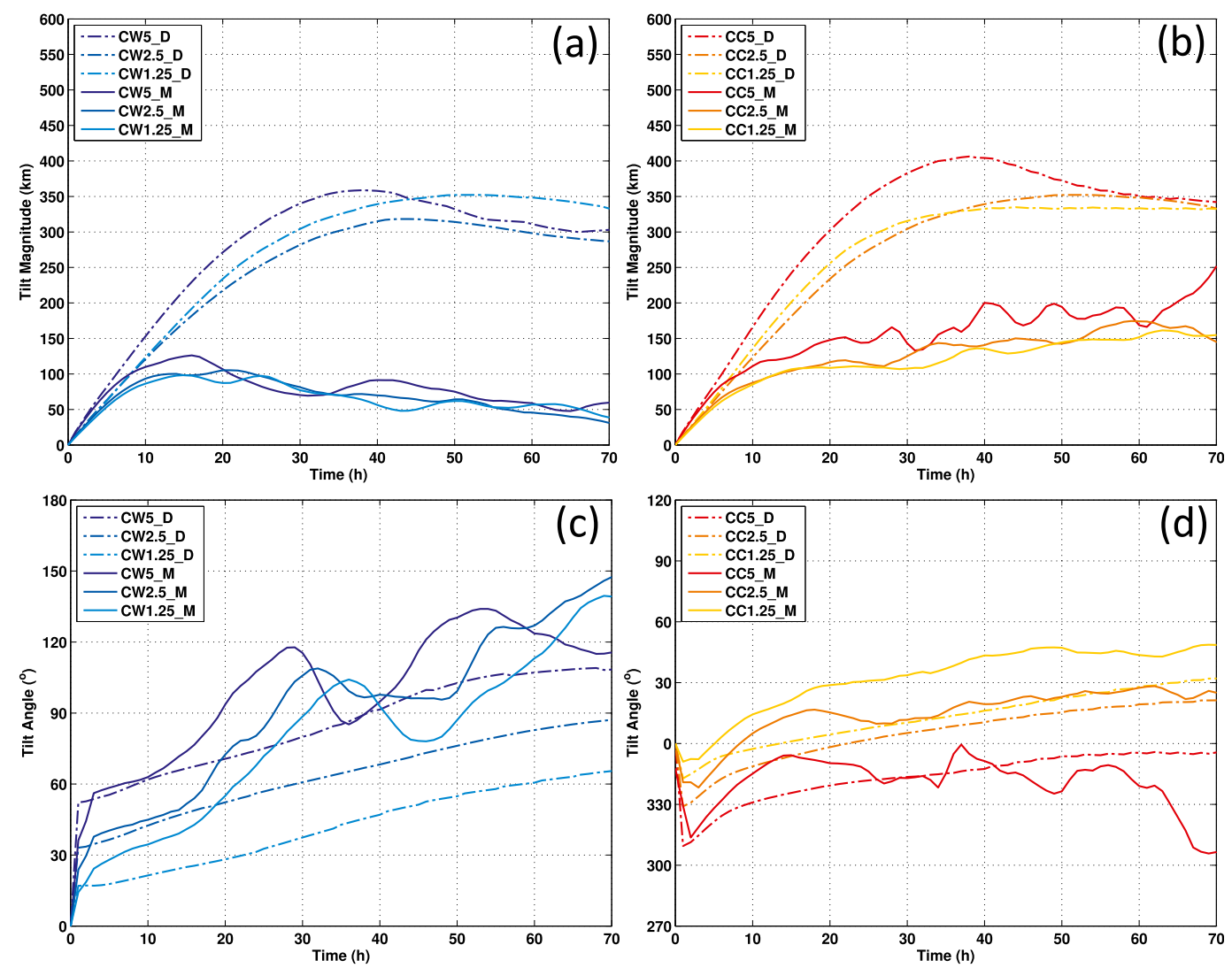

FIG. 13. Time evolution of (a),(b) overall vortex tilt $(0-8 \mathrm{~km})$ magnitude $(\mathrm{km})$ and $(\mathrm{c}),(\mathrm{d})$ tilt direction $\left(^{\circ}\right)$ for moist (solid line) and dry (dash-dotted line) simulations: (a) tilt magnitude in CW hodographs, (b) tilt magnitude in $\mathrm{CC}$ hodographs, (c) tilt direction in $\mathrm{CW}$ hodographs, and (d) tilt direction in CC hodographs. The tilt angle is calculated counterclockwise from east (i.e., $0^{\circ}$ for east, $90^{\circ}$ for north, $180^{\circ}$ for west, and $270^{\circ}$ for south). The suffix "_D" denotes results from dry simulations and "_M" denotes results from the corresponding moist simulations.

circulation and prevents the amplitude of overall vortex tilt from increasing rapidly.

The second effect is that enhanced coupling also leads to higher precession rates during the early stage (hours $0-15)$. The overall vortex tilt in all CC hodographs and CW1.25 precesses faster than in the corresponding dry simulations from hour 5 to 15 (Figs. 13c,d). The precession rates in CW2.5 and CW5 are generally the same as the dry simulations during this period. After hour 15, the precession rates of overall vortex tilt further accelerate in CW hodographs (Fig. 13c). To explore whether convective heating favors precession, we perform sensitivity simulations by reducing the convective heating from hours 15 to 25 in the CW2.5 simulation (see details in section 2). We choose CW2.5 to conduct sensitivity experiments because the overall vortex tilt in this simulation has a moderate precession rate (compared to CW1.25 and CW5) and ends up oriented upshear. Sensitivity simulations based on CW1.25 and CW5 lead to similar results. After convective heating is suppressed, the precession rate remains the same as in CW2.5 from hours 15 to 20 and then begins to decrease after hour 20 (Fig. 14a). The overall vortex tilt reaches the left-ofshear region $\left(90^{\circ}\right)$ around hour 35 , about $10 \mathrm{~h}$ later than in CW2.5 (Fig. 14a). The leading edge of the convective cluster also retrogresses after latent heating is weakened (not shown). As a result, the magnitude of the vortex tilt increases and its decrease begins later (Fig. 14b). The TC intensity also weakens in response to the delayed precession and increased vortex tilt magnitude after reducing the diabatic heating (not shown). These sensitivity simulations suggest a favorable role for convective heating in supporting the continuous precession of vortex tilt in CW hodographs. Another interesting feature is that the overall vortex tilt still precesses into the upshear region in CW2.5_0DH, in which all the convective heating has been turned off during hours 15-20. This strongly indicates that dry dynamics still have an effect in moist simulations. However, convective heating does not always favor the precession of vortex tilt. After hour 15, the precession rates in CC hodographs decrease to zero (CC1.25) or even become negative (CC2.5 and CC5), 

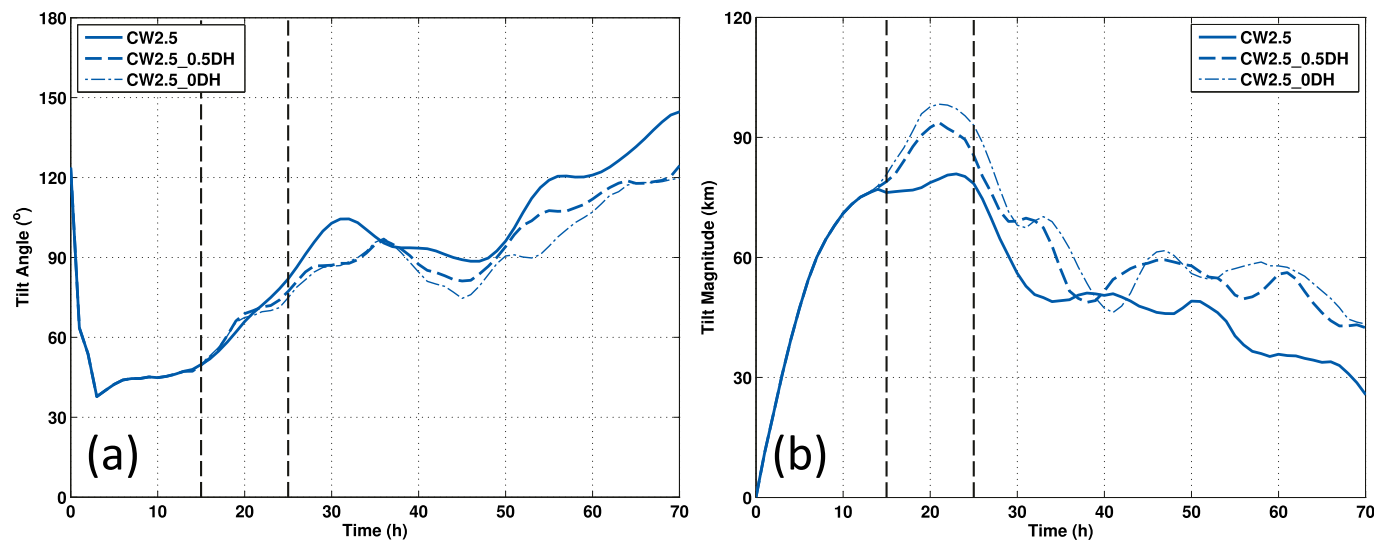

FIG. 14. Time evolution of (a) overall vortex tilt $(0-8 \mathrm{~km})$ direction $\left(^{\circ}\right)$ and (b) tilt magnitude $(\mathrm{km})$ for CW2.5 (blue solid) and the latent heating sensitivity simulations of CW2.5; i.e., CW2.5_0.5DH (blue dashed) and CW2.5_0DH (blue dashed-dotted). The two black vertical dashed lines denote the times at which the deactivation of diabatic heating begins $(15 \mathrm{~h})$ and ends $(25 \mathrm{~h})$

indicating that the tilted vortex stops precessing cyclonically and is pulled back toward the downshear-right region (Fig. 13d). This happens during the period when the convection becomes organized both in the radially outer region and in the azimuthally right-of-shear region (Fig. 6). Continuous organization of convection in CC hodographs results in stronger convective heating in the outer region. Figure 15 shows results from an isentropic analysis (e.g., Pauluis and Mrowiec 2013) of diabatic heating in the outer region $(100-200 \mathrm{~km})$ during hours 15-30. Isentropic analysis facilitates a separation of air parcels between warm, moist updrafts and cold, dry downdrafts that are fundamental aspects of moist convection and has been applied in recent studies of TCs (e.g., Mrowiec et al. 2016; Fang et al. 2017). It provides a cleaner way to compare the magnitudes of diabatic


FIG. 15. Isentropic distribution of time-averaged (hours 15-30) diabatic heating ( $\mathrm{K} \mathrm{s}^{-1}$ ) within 100-200 km of the vortex center at 2-km height: (a) CW1.25, (b) CW2.5, (c) CW5, (d) CC1.25, (e) CC2.5, and (f) CC5. The abscissa is the equivalent potential temperature (EPT). The black solid line represents the domain-averaged vertical profile of EPT. 

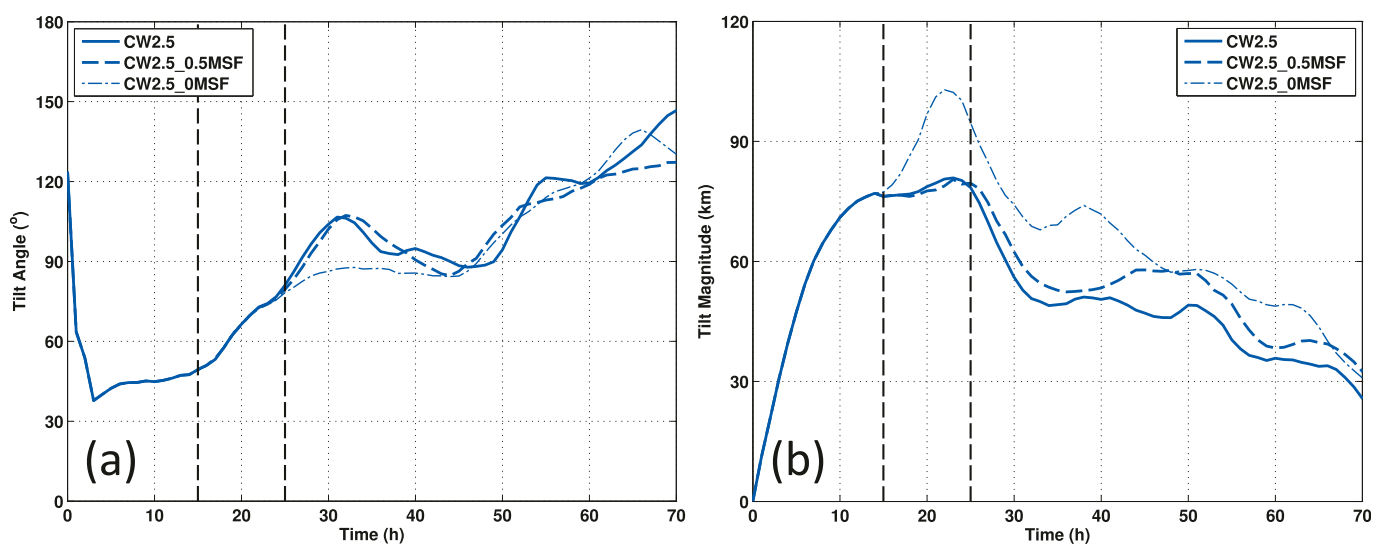

FIG. 16. Time evolution of (a) overall vortex tilt $(0-8 \mathrm{~km})$ direction $\left(^{\circ}\right)$ and $(\mathrm{b})$ tilt magnitude $(\mathrm{km})$ for CW2.5 (blue solid) and the surface heat flux sensitivity simulations of CW2.5; i.e., CW2.5_0.5MSF (blue dash) and CW2.5_0MSF (blue dashed-dotted). The two black vertical dashed lines denote the times at which the deactivation of surface heat fluxes begins $(15 \mathrm{~h})$ and ends $(25 \mathrm{~h})$.

heating in ascending airstreams between the simulations with different hodographs. The magnitudes of diabatic heating in CC hodographs are almost 2 times those in CW hodographs, particularly above $5 \mathrm{~km}$ (Figs. 15c-e). Strong convective heating in the outer region induces secondary circulations that weaken the radial inflow toward the TC center and suppress vertical motion in the inner region. Therefore, the persistence of convection in the outer region from the right-of-shear region to the downshear region has a negative impact on inner-core convection and explains the weakening of convection with time at smaller radii in CC hodographs (Fig. 6). In addition, strong convective heating above the midlevel generates cyclonic vorticity radially outward, thus increasing the magnitude of the overall vortex tilt and inhibiting tilt precession (Figs. 13b,d).

In addition to the effects of convective heating, it is reasonable to hypothesize that differences in the distribution of surface heat flux also contribute to differences in precession rates, as the surface heat flux in CW hodographs is stronger and closer to the upshear region than in CC hodographs (Fig. 10). Although the position and strength of strong surface heat fluxes are controlled primarily by the distribution of convection (see section 3 ), the feedback from surface heat fluxes may contribute to the continuous advancement of convective clusters in $\mathrm{CW}$ hodographs, as air parcels with large surface heat fluxes can be ingested into the TC core more frequently (ON16). However, it is unclear whether convective heating or the feedback from strong surface heat fluxes is more important for the continuous precession of overall vortex tilt. To investigate this, sensitivity simulations CW2.5_0.5MSF and CW2.5_0MSF are performed by removing the strong surface heat flux in the downstream region of the convective cluster during hours $15-25$, based on the CW2.5 simulation (see section 2). Results show that the evolution of vortex tilt in the sensitivity simulations, in terms of both precession rate and magnitude, generally remain the same as in the control simulation (CW2.5) throughout the integration except in CW2.5_0SF, in which all the surface heat flux is turned off (Fig. 16). Furthermore, the leading edge of convective clusters in the sensitivity experiments stays close to that in CW2.5 and the TC intensity changes little during this period though it weakens later (not shown). This suggests that it is the convective heating, rather than the strong surface heat flux in the downstream region of the convective cluster, that plays a leading role of controlling the precession rate of overall vortex tilt. Strong surface heat fluxes may provide favorable environments for convection organization in upshear regions but do not directly affect the precession of overall vortex tilt. These fluxes will provide energy for convection and affect the precession through diabatic heating at later stages.

\section{Discussion}

Vortex tilt precession and upshear propagation of convection are key processes by which TCs intensify in vertical wind shear and have been the focus of recent studies. Munsell et al. (2017) emphasized the role of vortex precession in aiding the upshear propagation of convection in their ensemble simulation of Hurricane Edouard (2014). Observational studies (Rogers et al. 2016; Zawislak et al. 2016) of Hurricane Edouard focused on environments, such as midlevel relative humidity in the upshear region and sea surface temperatures in the right-of-shear region, that support the persistence of deep convection in the upshear region and thus contribute to vortex tilt precession and TC intensification. Using 
idealized simulations, ON14 and ON16 emphasized the importance of various structures, including the distributions of helicity and convection and associated surface heat flux relative to the shear vector, in assisting the upshear advancement of convection in directional shear flows. Therefore, it is unclear if the propagation of convection into the upshear region is a result or a cause of the overall vortex tilt precession.

Here, we propose that these two processes closely interact with each other in directional shear flows, both constructively and destructively, depending on convection organization. This study investigates the dynamics that result in distinct TC structural features and how these structures couple with the overall vortex tilt through feedbacks from convective heating in directional shear flows. The position and organization of convective clusters in directional shear flows are first determined as a balanced response to the vortex tilt and are then influenced by TC movement and other dynamics. Convective heating plays an important role in coupling of vortices at different levels and also affects vortex tilt precession. Whether convective heating favors the continuous precession of vortex tilt depends on the organization of convection, which is controlled by both dry and moist dynamics. In CW hodographs, favorable convection organization enhances the feedback from convective heating and induces the overall vortex tilt to advance into a region with strong surface heat flux and a humid midtroposphere, favoring further organization and a strengthening of convection, thus forming a positive feedback. In CC hodographs, unfavorable organization in the azimuthally upwind region and in the radially outward region of convective clusters makes the precession of vortex tilt more difficult. This organization acts to vertically decouple the vortex and thus slows the precession of overall vortex tilt. In addition, the thermodynamic environment (a weak surface heat flux and dry midtroposphere) in the downstream region of the overall vortex tilt is less conducive to persistent deep convection. As a result, a negative feedback is established and hinders the precession of vortex tilt and the advancement of convective clusters in $\mathrm{CC}$ hodographs.

A recent observational study (B. Chen et al. 2018) found that the relative configuration of low-level mean flow (LMF; i.e., 850-hPa mean flow) and deep-layer vertical wind shear is important in determining TC structure and intensity change. The LMF directed to the left (right) of the deep-layer shear is called left-of-shear (right-ofshear) LMF, corresponding to the LMF in CW (CC) hodographs. A left-of-shear LMF favors TC intensification, whereas a right-of-shear orientation of LMF favors an increase in TC size. This is consistent with our findings for directional shear flows. In CW hodographs, TC-relative LMF is directed toward a left-of-shear orientation and supports the continuous precession of convective clusters into the upshear region, leading to TC intensification. In CC hodographs, TC-relative LMF is oriented toward the right-of-shear region, favoring convection organization in the outer region to broaden the PV skirt and thus leads to increases in size rather than intensification.

\section{Summary}

This study investigated the coupling between vortex tilt and convection organization and its impact on TC intensification in directional shear flows. A comparison with dry simulations revealed the importance of the feedback from moist convection through convective heating, although dry dynamics can explain a large part of the TC structural differences between $\mathrm{CW}$ and $\mathrm{CC}$ hodographs.

During the early stage of development, the overall vortex tilt is generally directed toward the downshearleft region in CW hodographs and the downshear-right region in $\mathrm{CC}$ hodographs. This is consistent with the balanced response to the height-dependent vortex tilt and explains subsequent differences in the azimuthal distribution of moist convection. Once the positions of convective clusters are determined, strong surface heat fluxes occur in the downstream region, primarily because of the thermodynamic disequilibrium reservoir established by low-entropy downdrafts associated with precipitation. Therefore, large variability in TC structures in directional shear flows during the early stage is well explained by vortex tilt-dominated dry dynamics, even in moist simulations.

Convective heating favors coupling between vortex centers at different levels and thus reduces the vortex tilt magnitude compared with dry simulations and then accelerates precession in both $\mathrm{CW}$ and $\mathrm{CC}$ hodographs during the early stage. Afterward in CW hodographs, the precession of vortex tilt, together with TC movement, favors organization of convection in the downstream region of overall vortex tilt because of the strong surface heat flux and moist midtroposphere. A positive feedback among vortex tilt, organized convection, and convective heating is established. As a result, the precession of vortex tilt is further accelerated and reaches the upshear-left region, which aids the reduction in vortex tilt and subsequently leads to intensification. However, in CC hodographs, the convective heating associated with the continuous organization of convection in outer regions and azimuthally upwind regions tends to vertically decouple the vortex and weakens 
their coupling. Given that the downstream region has both a weak surface heat flux and a dry midtroposphere, a negative feedback is established that concentrates convective heating mainly in the downshear-right and radially outward region. Consequently, the cyclonic precession of vortex tilt through the downshear-left region gradually slows, or even retrogresses to the downshearright region. This results in a continuous increase in overall vortex tilt magnitude by deep-layer shear and thus prevents TC intensification in CC hodographs.

Acknowledgments. We thank Dr. David S. Nolan and Dr. Matthew J. Onderlinde for their suggestions on the implementation of PDS method in the WRF Model and Dr. Nadir Jeevanjee for providing the code to decompose the vertical acceleration into thermodynamic and dynamical components. The first author also thanks Dr. Christopher E. Holloway for helpful discussion. The authors also thank two anonymous reviewers for their critical comments that improve our manuscript. This work is jointly supported by the National Key R\&D Program of China under Grant 2017YFC1501601, National Key Project for Basic Research (973 Project) under Grant 2015CB452803, and the National Natural Science Foundation of China (41505044, 41575053, 41675053).

\section{REFERENCES}

Chen, B.-F., C. A. Davis, and Y.-H. Kuo, 2018: Effects of low-level flow orientation and vertical wind shear on the structure and intensity of tropical cyclones. Mon. Wea. Rev., 146, 2447-2467, https://doi.org/10.1175/MWR-D-17-0379.1.

Chen, X., Y. Wang, J. Fang, and M. Xue, 2018: A numerical study on rapid intensification of Typhoon Vicente (2012) in the South China Sea. Part II: Roles of inner-core processes. J. Atmos. Sci., 75, 235-255, https://doi.org/10.1175/JAS-D-17-0129.1.

Davis, A. C., 2015: The formation of moist vortices and tropical cyclones in idealized simulations. J. Atmos. Sci., 72, 3499-3516, https://doi.org/10.1175/JAS-D-15-0027.1.

Fang, J., O. M. Pauluis, and F. Zhang, 2017: Isentropic analysis on the intensification of Hurricane Edouard (2014). J. Atmos. Sci., 74, 4177-4197, https://doi.org/10.1175/JAS-D-17-0092.1.

Frank, W. M., and E. A. Ritchie, 1999: Effects of environmental flow upon tropical cyclone structure. Mon. Wea. Rev., 127, 2044-2061, https://doi.org/10.1175/1520-0493(1999)127<2044: EOEFUT $>2.0 . \mathrm{CO} ; 2$.

Gu, J.-F., Z.-M. Tan, and X. Qiu, 2015: Effects of vertical wind shear on inner-core thermodynamics of an idealized simulated tropical cyclone. J. Atmos. Sci., 72, 511-530, https://doi.org/ 10.1175/JAS-D-14-0050.1.

,-- , and _ 2016: Quadrant-dependent evolution of lowlevel tangential wind of a tropical cyclone in the shear flow. J. Atmos. Sci., 73, 1159-1177, https://doi.org/10.1175/JAS-D15-0165.1.

_ - _ and - , 2018: The evolution of vortex tilt and upward motion of tropical cyclones in directional shear flows. J. Atmos. Sci., 75, 3565-3578, https://doi.org/10.1175/ JAS-D-18-0024.1.
Hide, R., 2002: Helicity, superhelicity and weighted relative potential vorticity: Useful diagnostic pseudoscalars? Quart. J. Roy. Meteor. Soc., 128, 1759-1762, https://doi.org/10.1002/ qj.200212858318.

Hong, S.-Y., and J.-O. J. Lim, 2006: The WRF single-moment 6-class microphysics scheme (WSM6). J. Korean Meteor. Soc., 42, 129-151.

—, Y. Noh, and J. Dudhia, 2006: A new vertical diffusion package with an explicit treatment of entrainment processes. Mon. Wea. Rev., 134, 2318-2341, https://doi.org/10.1175/ MWR3199.1.

Jeevanjee, N., and D. M. Romps, 2015: Effective buoyancy, inertial pressure, and the mechanical generation of boundary layer mass flux by cold pools. J. Atmos. Sci., 72, 3199-3213, https:// doi.org/10.1175/JAS-D-14-0349.1.

Mrowiec, A. A., O. M. Pauluis, and F. Zhang, 2016: Isentropic analysis of a simulated hurricane. J. Atmos. Sci., 73, 1857-1870, https://doi.org/10.1175/JAS-D-15-0063.1.

Munsell, E. B., F. Zhang, J. A. Sippel, S. A. Braun, and Y. Weng, 2017: Dynamics and predictability of the intensification of Hurricane Edouard (2014). J. Atmos. Sci., 74, 573-593, https:// doi.org/10.1175/JAS-D-16-0018.1.

Nolan, D. S., 2011: Evaluating environmental favorableness for tropical cyclone development with the method of pointdownscaling. J. Adv. Model. Earth Syst., 3, M08001, https:// doi.org/10.1029/2011MS000063.

Onderlinde, M. J., and D. S. Nolan, 2014: Environmental helicity and its effects on development and intensification of tropical cyclones. J. Atmos. Sci., 71, 4308-4320, https://doi.org/10.1175/ JAS-D-14-0085.1.

$\longrightarrow$, and — 2016: Tropical cyclone-relative environmental helicity and the pathways to intensification in shear. J. Atmos. Sci., 73, 869-890, https://doi.org/10.1175/JAS-D-15-0261.1.

Pauluis, O. M., and A. A. Mrowiec, 2013: Isentropic analysis of convective motions. J. Atmos. Sci., 70, 3673-3688, https:// doi.org/10.1175/JAS-D-12-0205.1.

Rappin, E. D., and D. S. Nolan, 2012: The effects of vertical shear orientation on tropical cyclogenesis. Quart. J. Roy. Meteor. Soc., 138, 1035-1054, https://doi.org/10.1002/qj.977.

Reasor, P. D., M. T. Montgomery, and L. D. Grasso, 2004: A new look at the problem of tropical cyclones in vertical wind shear flow: Vortex resiliency. J. Atmos. Sci., 61, 3-22, https://doi.org/ 10.1175/1520-0469(2004)061<0003:ANLATP>2.0.CO;2.

Riemer, M., 2016: Meso- $\beta$-scale environment for the stationary band complex of vertically sheared tropical cyclones. Quart. J. Roy. Meteor. Soc., 142, 2442-2451, https://doi.org/10.1002/qj.2837.

Rogers, R. F., J. A. Zhang, J. Zawislak, H. Jiang, G. R. Alvey III, E. J. Zipser, and S. N. Stevenson, 2016: Observations of the structure and evolution of Hurricane Edouard (2014) during intensity change. Part II: Kinematic structure and the distribution of deep convection. Mon. Wea. Rev., 144, 3355-3376, https://doi.org/10.1175/MWR-D-16-0017.1.

Rotunno, R., J. B. Klemp, and M. L. Weisman, 1988: A theory for strong, long-lived squall lines. J. Atmos. Sci., 45, 463-485, https://doi.org/10.1175/1520-0469(1988)045<0463:ATFSLL> 2.0.CO;2.

Schecter, D. A., M. T. Montgomery, and P. D. Reasor, 2002: A theory for the vertical alignment of a quasigeostrophic vortex. J. Atmos. Sci., 59, 150-168, https://doi.org/10.1175/15200469(2002)059<0150:ATFTVA > 2.0.CO;2.

Skamarock, W. C., and Coauthors, 2008: A description of the Advanced Research WRF version 3. NCAR Tech. Note NCAR/TN-475+STR, 113 pp., https://doi.org/10.5065/ D68S4MVH. 
Stevenson, S. N., K. L. Corbosiero, and J. Molinari, 2014: The convective evolution and rapid intensification of Hurricane Earl (2010). Mon. Wea. Rev., 142, 4344-4380, https://doi.org/ 10.1175/MWR-D-14-00078.1.

Tan, Z.-M., and R. Wu, 1994: Helicity dynamics of atmospheric flow. Adv. Atmos. Sci., 11, 175-188, https://doi.org/10.1007/ BF02666544.

Wang, Y., Y. Rao, Z.-M. Tan, and D. Schönemann, 2015: A statistical analysis of the effects of vertical wind shear effects on tropical cyclone intensity change over the western North Pacific. Mon. Wea. Rev., 143, 3434-3453, https://doi.org/ 10.1175/MWR-D-15-0049.1.

Zawislak, J., H. Jiang, G. R. Alvey III, and E. J. Zipser, 2016: Observations of the structure and evolution of Hurricane Edouard (2014) during intensity change. Part I: Relationship between the thermodynamic structure and precipitation. Mon. Wea. Rev., 144, 3333-3354, https://doi.org/10.1175/MWR-D16-0018.1. 